7 Reddy BS, Maruyama H, Kelloff G. Dose-related inhibition of colon carcinogenesis by dietary piroxicam, a nonsteroidal antinflammatory drug, during different stages of rat colon tumor development. Cancer Res 1987;47:5340-6.

8 Reddy BS, Nayini J, Tokumo K, Rigotty J, Zang E, Kelloff G. Chemoprevention of colon carcinogenesis by concurrent administration of piroxicam, a nonsteroidal antinflammatory drug with $D, L-\alpha$-difluoromethylornithine, an ornithine decarboxylase inhibitor, in diet. Cancer Res 1990;50:2562-8.

9 Metzger U, Meier J, Uhlschmid G, Weihe H. Influence of various prostaglandin synthesis inhibitors on DMH-induced rat colon cancer. Dis Colon Rectum 1984;27:366-9.

10 Waddell WR, Loughry RW. Sulindac for polyposis of the colon. I Surg Oncol 1983;24:83-7.

11 Labayle D, Fischer D, Vielh P, Drouhin F, Pariente A, Bories C, et al. Sulindac causes regression of rectal polyps in familial adenomatous polyposis. Gastroenterology 1991;101:635-9.

12 Nugent KP, Farmer KCR, Spigelman AD, Williams CB, Phillips RKS Randomised controlled clinical trial of Sulindac on intestinal polyposis in FAP. Gut 1992;33:S33.

13 Giardiello FM, Hamilton SR, Krush AJ, Piantadosi S, Hylind LM, Celano P, et al. Treatment of colonic and rectal adenomas with sulindae in familial adenomatous polyposis. N Engl f Med 1993;328:1313-6.

14 Kune GA, Kune S, Watson LF. Colorectal cancer risk, chronic illnesses, operations, and medications: case control results from the Melbourne Colorectal Cancer Study. Cancer 1988;48:399-404.

15 Rosenberg L, Palmer JR, Zauber AG, Warshauer ME, Stolley PD, Shapiro S. A hypothesis: nonsteroidal anti-inflammatory drugs reduce the incidence of large bowel-cancer. $\mathcal{F}$ Natl Cancer Inst 1991;83:355-8.

16 Thun MJ, Namboodiri MM, Heath CW. Aspirin use and reduced risk of colon cancer. N Engl f Med 1991;325:1593-6.

17 Paganini-Hill A, Hsu G, Ross RK, Henderson BE. Aspirin use and incidence of large-bowel cancer in a California retirement community. $\mathcal{f}$ Natl Cancer Inst 1991;83:1182-3.

18 Little J, Logan RFA, Hawtin PG, Hardcastle JD, Turner ID. Colorectal adenomas and diet: a case-control study of subjects participating in the Nottingham faecal occult blood screening programme. $B r F$ Cancer 1993;67:177-84.
19 Hardcastle JD, Thomas WM, Chamberlain J, Pye G, Sheffield J, James PD, et al. Randomised, controlled trial of faecal occult blood screening for col. Randomised, Conter Cock the Cancer, 1988 .

21 Baker RJ, Clarke MRB, Nelder JA. GLIM: the generalised linear interactive modelling system. Oxford: Numerical Algorithms Group, 1985. (GLIM 3.77 Manual and Macro Library Release 1.1.)

22 Statistics and Epidemiology Research Corporation. EGRET (Epidemiological Graphics, Estimation, and Testing Package). Seattle: SERC, 1991.

23 Armitage N, Hardcastle JD, Amar SS, Balfour TW, Haynes J, James PD. A comparison of an immunological faecal occult blood test Fecatwin sensitive/ FECA EIA with Haemoccult in population screening for colorectal cancer. Brf Cancer 1985;51:799-804.

24 Rees WD, Turnberg LA. Reappraisal of the effects of aspirin on the stomach. Lancet 1980;ii:410-3.

25 Doran J, Hardcastle JD. Bleeding patterns in colorectal cancer: the effect of aspirin and the implications for faecal occult blood testing. $\mathrm{Br} f$ Surg 1982;69:711-3.

26 Norfleet RG. $1,300 \mathrm{mg}$ of aspirin daily does not cause positive fecal Hemoccult tests. $\mathcal{F C l i n}$ Gastroenterol 1983;5:123-5.

27 Thomas WM, Hardcastle JD. Role of upper gastrointestinal investigations in a screening study for colorectal neoplasia. Gut 1990;31:1294-7.

28 Ransohoff DF, Lang CA. Small adenomas detected during fecal occult blood test screening for colorectal cancer: the impact of serendipity. $\mathscr{f} A M A$ 1990;264:76-8.

29 Simon JB. Colonic polyps, occult blood, and chance. FAMA 1990;264:84-

30 Pye G, Ballantyne KC, Armitage NC, Hardcastle JD. Influence of nonsteroidal anti-inflammatory drugs on the outcome of faecal occult blood tests in screening for colorectal cancer. $B M 7$ 1987;294:1510-1.

31 DeRubertis FR, Craven PA, Saito R. 16,16-Dimethyl prostaglandin E suppresses the increases in the proliferative activity of rat colonic epithelium induced by indomethacin and aspirin. Gastroenterology 1985;89:1054-63.

(Accepted 25 May 1993)

\section{INSERM U 360,}

\section{Recherches}

Epidémiologiques en

Neurologie et

Psychopathologie,

Villejuif, France

Christophe Tzourio, senior

registrar

Jean-Baptiste Hubert, research fellow

Annick Alpérovitch, director of research

Service de Neurologie, Hôpital Saint-Antoine,

Paris, France

Serge Iglesias, registrar

Alain Tehindrazanarivelo,

senior registrar

Valérie Biousse, registrar

Marie-Germaine Bousser,

professor of neurology

Service de Neurologie, Hôpital Lariboisière, Paris, France

Jean-Marc Visy, senior

registrar

France Woimant, consultant

Correspondence to:

Dr C Tzourio, INSERM

U 360, Recherches

Epidémiologiques en

Neurologie et

Psychopathologie, 16 av

Paul Vaillant Couturier,

Cedex 94807 Villejuif,

France.

$B M F$ 1993;307:289-92

\title{
Migraine and risk of ischaemic stroke: a case-control study
}

\author{
Christophe Tzourio, Serge Iglesias, Jean-Baptiste Hubert, Jean-Marc Visy, Annick Alpérovitch,
} Alain Tehindrazanarivelo, Valérie Biousse, France Woimant, Marie-Germaine Bousser

\section{Abstract}

Objectives-To determine whether migraine is a risk factor for ischaemic stroke.

Design-A case-control study.

Setting-Two hospitals in Paris.

Subjects-212 patients with stroke (137 men and 75 women) and 212 controls matched for sex, age (to within five years), and history of hypertension.

Main outcome measures-Ischaemic stroke, confirmed by brain computed tomography or magnetic resonance imaging, and history of headache, recorded with structured questionnaire during interview.

Results-Prevalence of migraine did not differ between patients with stroke and controls: 18/137 $v$ $17 / 137$ for men (odds ratio 1.1 (95\% confidence interval 0.5 to $2 \cdot 2$ ), $p=0.86) ; 23 / 75 v 17 / 75$ for women (odds ratio $1.6(0.7$ to 3.5$), \mathrm{p}=0.24)$; and $41 / 212 v 34 /$ 212 for both sexes (odds ratio $1.3(0.8$ to $2 \cdot 3), p=$ $0.33)$. When subjects were split into two age groups, however, prevalence of migraine was significantly higher among younger women (aged <45) with stroke compared with their controls $(13 / 20 v 6 / 20$, odds ratio $4.3(1.2$ to $16 \cdot 3), p=0.03)$. Furthermore, the risk of ischaemic stroke was higher among younger women who smoked $(7 / 20 v 1 / 20$, odds ratio $10 \cdot 2(1 \cdot 1$ to $93 \cdot 3))$.

Conclusions-Prevalence of migraine was not different between patients with stroke and matched controls except among women aged $<45$, when migraine and stroke were significantly associated.

\section{Introduction}

Besides being a rare but well documented cause of cerebral infarction - migrainous infarct-migraine has episodically been suggested as a risk factor for stroke. Indeed, the vasomotor changes ${ }^{1}$ and modifications of platelet aggregability ${ }^{2}$ that occur during migraine could cause an ischaemic stroke. Few epidemiological studies have addressed the question of the link between migraine and stroke, and their results are not consistent. As examples of the wide range of values observed, the risk of stroke associated with migraine was $1 \cdot 2$ for women aged under 45 not using oral contraceptives ${ }^{4}$ and was 31.3 for a subgroup of patients without vascular risk factors. ${ }^{5}$

The present study was performed to address this issue and was the first to be based on the diagnostic criteria for migraine recently proposed by the International Headache Society. ${ }^{6}$

\section{Patients and methods}

All patients aged $18-80$ successively admitted to two Paris hospitals with a diagnosis of ischaemic stroke over 24 months were included in the study provided they were willing and able to answer the questionnaire. Ischaemic stroke was defined clinically, according to the World Health Organisation's criteria, ${ }^{7}$ and was confirmed in all patients by computed tomography or magnetic resonance imaging of the brain. Patients with transient ischaemic attacks or cerebral venous thrombosis were excluded. Controls were selected from patients admitted to the hospitals with benign rheumatological conditions or for routine surgical procedures excluding vascular surgery. Patients with a history of stroke were excluded. Controls were matched with patients with stroke for age (to within five years), sex, and history of hypertension.

Each subject's history of headache was recorded during an interview in hospital by a neurologist with a highly structured questionnaire. This covered all of the International Headache Society's diagnostic criteria for migraine with or without aura and different subtypes. ${ }^{6}$ The subjects were not aware of the final aim of the study: they were just asked if they wanted to participate in a neuroepidemiological study, and none 
refused. Other details were also recorded during the interview: past or current hypertension (blood pressure $>160 \mathrm{~mm} \mathrm{Hg}$ systolic or $>95 \mathrm{~mm} \mathrm{Hg}$ diastolic on at least two occasions), its duration, and whether it was treated; hypercholesterolaemia; diabetes mellitus; past or current smoking; past or current use of oral contraceptives; and chronic alcoholism (intake of $\geqslant 500 \mathrm{~g}$ alcohol per week for men and $\geqslant 250 \mathrm{~g}$ per week for women).

We calculated the number of subjects needed to demonstrate a twofold increase of stroke among the patients with migraine, assuming a $10 \%$ prevalence of migraine in the control group, a significance level of $5 \%$ (type I error), and a power of $80 \%$ : this required 220 patients in each group. Causes of stroke in young people are clearly different from those observed later in life: after an overall analysis, we therefore divided the sample into two age groups $(<45$ and $\geqslant 45)$ and compared the prevalence of migraine between cases and controls in the different subgroups.

We used Statistical Analysis System ${ }^{8}$ for all analyses except for unconditional multiple logistic regression, for which we used Biomedical Computer Programs. ${ }^{9}$ Categorical variables were compared by Fisher's test of exact probability (two tailed), Pearson's $\chi^{2}$ test, or McNemar's test. When possible we used paired tests in the univariate analysis. Odds ratios were used as a close approximation to relative risk. The odds ratios after adjustment for possible confounding variables were calculated by unconditional multiple logistic regression. ${ }^{10}$ Hypothesis testing and estimation of the $95 \%$ confidence interval were carried out by using the estimated standard error for the estimated logistic coefficients.

\section{Results}

Although 228 patients with stroke were recruited, the results for 16 were excluded: eight because of inadequate data recording and eight because no matched control could be found. The analysis was therefore carried out with 212 patients with stroke (137 men and 75 women) and their matched controls. Table I shows the subjects' baseline characteristics: the two groups were similar in age, sex, and prevalence and duration of hypertension. Histories of cigarette smoking, hypercholesterolaemia, and diabetes mellitus were more common among the patients with stroke, and the differences were significant for smoking and diabetes in men and for hypercholesterolaemia in women.

In order to identify confounding factors-factors linked with both migraine and ischaemic stroke-we compared subjects with a history of migraine with those without (table II). Age and sex-two factors linked with the risk of stroke-were the only potential confounders: subjects with migraine were younger and

TABLE I-Comparison of characteristics of 212 patients with ischaemic stroke (137 men and 75 women) and 212 controls matched for sex, age, and history of hypertension. Values are numbers of subjects unless stated otherwise

\begin{tabular}{|c|c|c|c|c|}
\hline & $\begin{array}{l}\text { Patients with } \\
\text { stroke }\end{array}$ & Controls & $\begin{array}{c}\text { Odds ratio } \\
\text { (95\% confidence } \\
\text { interval) }\end{array}$ & p Value \\
\hline \multicolumn{5}{|l|}{ Men: } \\
\hline Mean (SD) age (years) & $55.5(13.6)$ & $56.4(13.4)$ & & \\
\hline History of hypertension & 54 & 54 & & \\
\hline Cigarette smoking & 60 & 37 & $2 \cdot 1(1.3$ to $3 \cdot 5)$ & 0.004 \\
\hline History of hypercholesterolaemia & 40 & 28 & $1.6(0.9$ to 2.7$)$ & 0.08 \\
\hline History of diabetes mellitus & 22 & 12 & $2 \cdot 1(1.0$ to 4.5$)$ & 0.05 \\
\hline Alcoholism (intake $>500 \mathrm{~g} /$ week) & 25 & 20 & $1.1(0.6$ to $2 \cdot 1)$ & 0.7 \\
\hline \multicolumn{5}{|l|}{ Women: } \\
\hline Mean (SD) age (years) & $56 \cdot 6(16 \cdot 1)$ & $56.4(16.0)$ & & \\
\hline History of hypertension & 36 & 36 & & \\
\hline Cigarette smoking & 20 & 11 & $2.8(1.0$ to 7.8$)$ & 0.04 \\
\hline History of hypercholesterolaemia & 31 & 17 & $3.2(1.3$ to 7.9$)$ & 0.01 \\
\hline History of diabetes mellitus & 10 & 10 & $1.0(0.4$ to 2.6$)$ & \\
\hline Alcoholism (intake $>250 \mathrm{~g} /$ week) & 2 & 0 & & 0.5 \\
\hline Use of oral contraceptives & 24 & 26 & $0.8(0.3$ to 2.0$)$ & 0.7 \\
\hline
\end{tabular}

were more likely to be women than those without migraine. Table III shows the prevalence of migraine among the patients with stroke and the controls: no association was found between migraine and ischaemic stroke. This was also true for the different subtypes of migraine: migraine without aura was present in 19 of the 212 patients with stroke and 23 of the 212 controls (odds ratio $0.8(95 \%$ confidence interval 0.4 to 1.5$)$ ); and migraine with typical aura was present in nine patients with stroke and seven controls (odds ratio 1.3 $(0.5$ to 3.8$))$. However, neurological symptoms that could be classified as migrainous aura without headache (code 1.2.5 of the International Headache Society's classification) were more common in the patients with stroke (13) than in the controls (four) (odds ratio 4.0 $(1 \cdot 1$ to $14 \cdot 2))$.

TABLE II-Comparison of 75 subjects with a history of migraine and 349 subjects without by main risk factors for ischaemic stroke. Values are numbers (percentages) of subjects unless stated otherwise

\begin{tabular}{lccl}
\hline & $\begin{array}{c}\text { With } \\
\text { migraine }\end{array}$ & $\begin{array}{c}\text { Without } \\
\text { migraine }\end{array}$ & p Value \\
\hline Male:female ratio & $35: 40$ & $239: 110$ & 0.001 \\
Mean (SD) age (years) & $49.3(15 \cdot 6)$ & $57.6(13.6)$ & 0.001 \\
History of hypertension & $30(40)$ & $150(43)$ & 0.7 \\
Cigarette smoking & $27(36)$ & $101(29)$ & 0.3 \\
$\begin{array}{l}\text { Use of oral contraceptives in women } \\
\text { aged <45 }\end{array}$ & $14(70)$ & $16(73)$ & 0.9 \\
\hline
\end{tabular}

TABLE III-Prevalence of migraine among 212 patients with ischaemic stroke (137 men and 75 women) and 212 matched controls. Values are numbers of subjects

\begin{tabular}{lcccc}
\hline & $\begin{array}{c}\text { Patients } \\
\text { with } \\
\text { stroke }\end{array}$ & Controls & $\begin{array}{c}\text { Odds ratio } \\
\text { (95\% confidence } \\
\text { interval) }\end{array}$ & p Value \\
\hline Men & 18 & 17 & $1.1(0.5$ to $2 \cdot 2)$ & 0.86 \\
Women & 23 & 17 & $1.6: 0.7$ to 3.5$)$ & 0.24 \\
Both sexes & 41 & 34 & $1.3(0.8$ to 2.3$)$ & 0.33 \\
\hline
\end{tabular}

We performed separate analyses of people aged under and over 45 . No association between migraine and ischaemic stroke was found with older men (odds ratio $1.4, p=0.47$ ), older women (odds ratio $0.9, \mathrm{p}=$ $0 \cdot 80$ ), older men and women combined (odds ratio $1 \cdot 1$, $\mathrm{p}=0.76$ ), and younger men (odds ratio $0.7, \mathrm{p}=0.33$ ). There was, however, a significant association between migraine and stroke in younger women (odds ratio 4.3 ( $95 \%$ confidence interval $1 \cdot 2$ to $16 \cdot 3)$ ), and this association persisted after adjustment for age and hypertension (adjusted odds ratio $4.9(1 \cdot 1$ to $21 \cdot 4)$ ). Table IV shows that prevalence of migraine was the only significant difference between younger women with stroke and their controls. The younger women's risk of ischaemic stroke was higher when they had histories of both migraine and smoking: seven of the 20 women with stroke had migraine and were current smokers compared with one of the controls (odds ratio $10 \cdot 2(1 \cdot 1$ to $93 \cdot 3)$ ).

\section{Discussion}

We found that the prevalence of migraine in the whole group of patients with ischaemic stroke was not different from that in the matched controls, so that migraine was not a risk factor for stroke. This result differs from the results of the few other epidemiological studies of this issue. The Collaborative Group for the Study of Stroke in Young Women found that migraine was a moderate risk factor for stroke (odds ratio 1.7 (95\% confidence interval $1 \cdot 2$ to $2 \cdot 6$ )) when patients with stroke were compared with controls in the community but not when they were compared with controls in hospital. ${ }^{4}$ The results are difficult to interpret because of methodological deficiencies: a high level of non-participation, lack of adequate 
TABLE IV-Comparison of main characteristics of 20 women aged $<45$ with ischaemic stroke and 20 matched controls. Values are numbers of subjects unless stated otherwise

\begin{tabular}{lcccc}
\hline & $\begin{array}{c}\text { Patients with } \\
\text { stroke }\end{array}$ & Controls & $\begin{array}{c}\text { Odds ratio } \\
(95 \% \text { confidence } \\
\text { interval) }\end{array}$ & p Value \\
\hline Mean (SD) age (years) & $36 \cdot 1(7 \cdot 1)$ & $36 \cdot 4(6.3)$ & & 0.7 \\
History of hypertension & 2 & 2 & $1.0(0.1$ to 7.9$)$ & 0.9 \\
Cigarette smoking & 10 & 8 & $1.5(0.4$ to $5 \cdot 2)$ & 0.5 \\
Use of oral contraceptives & 15 & 13 & $1.6(0.4$ to 6.4$)$ & 0.5 \\
History of migraine & 13 & 6 & $4.3(1.2$ to 16.3$)$ & 0.03 \\
\hline
\end{tabular}

imaging of the brain, diagnosis of migraine based on self reported symptoms, and no indication of the comparability of the patients with ischaemic stroke and the controls. Henrich and Horwitz compared 89 patients with ischaemic stroke aged 15-65 with 178 controls. ${ }^{5}$ They found that "classic" migraine was more common in the patients with stroke (odds ratio $2.6(1 \cdot 1$ to $6 \cdot 6)$ ), but this relation did not persist after adjustment for other risk factors. In the subgroup of patients without vascular risk factors a high risk of ischaemic stroke was found in association with classic migraine (odds ratio 31.3 (4.5 to 216.7 )), but the number of subjects was small, the groups were unbalanced (five patients with stroke and 48 controls), and the authors did not check if the groups were of similar ages and sex ratios (two potentially major confounding variables).

Our study had three original features. Firstly, we used the International Headache Society's criteria for migraine, which are now the reference criteria. ${ }^{6}$ The prevalence of migraine in the whole control group was $16 \%(34 / 212)$ and in young control women was $30 \%$ $(6 / 20)$, results similar to those obtained in other studies using the same criteria. ${ }^{11}$ Secondly, in order to limit selection bias, all the patients with stroke were successively enrolled in two different departments of neurology. Thirdly, patients with stroke and controls were matched not only for age and sex but also for hypertension, which is a major risk factor for stroke. The existence of a link between migraine and hypertension is unlikely ${ }^{12-14}$ but has been debated. ${ }^{15} 16$ The aim of matching was to obtain comparable groups and to avoid an unbalanced pattern that could not be easily overcome by adjustment. The prevalence of other risk factors was similar to that in other studies ${ }^{717}$ and was balanced between the two groups.

When we split our subjects according to type of migraine we found that migrainous aura without headache was significantly more common among patients with stroke, and when we split subjects according to age we found an association between migraine and stroke in younger women. The results for migrainous aura without headache are, however, difficult to interpret because transient ischaemic attacks can have identical symptoms.

Although smoking was not a significant risk factor in younger women in our study, when current smoking and migraine were both present the risk of stroke was particularly high. Chen et al suggested that people with migraine might have a higher risk than others of

\section{Public health implications}

- Migraine has been suggested as a risk factor for ischaemic stroke

- Overall, we found no association between migraine and ischaemic stroke

- Among women aged $<45$, however, migraine and stroke were significantly associated, especially among young women who smoked

- Ischaemic stroke is not associated with migraine except possibly among young women developing diseases in response to cigarette smoking, but they did not specifically study stroke because the number of events in their sample was too small. ${ }^{14}$ The Collaborative Group for the Study of Stroke in Young Women did not assess the risk of the association between migraine and tobacco. ${ }^{4}$

Like others, we did not find any link between migraine and oral contraceptives in younger women. ${ }^{15}$ In another study the use of oral contraceptives was associated with an increased risk of stroke, ${ }^{4}$ but only $13 \%-15 \%$ of the study's controls used oral contraceptives compared with $65 \%$ in our study. The use of oral contraceptives was so widespread in our study that it was not possible to individualise their effects.

The number of patients in each of our groups (212) did not quite reach the calculated goal of 220 . Since the prevalence of migraine was higher than expected, however, the final power was satisfactory $(91 \%)$. The number of subjects in each subgroup of young women was relatively small (20). Results for this subgroup must therefore be treated cautiously even though they were significant, and they need to be confirmed by larger studies before firm conclusions can be drawn.

Bias could have resulted from the observers not having been blind to the clinical status of the subjects and therefore looking for migraine more actively in patients with stroke. To control for this the interviews were highly structured with 30 different questions on headache. The fact that a significant link between migraine and stroke was only found in one subgroup of patients makes this bias unlikely. Another potential bias was recall: the patients with stroke suffered from a brain disease and so may have been more prone to recall their headache than the controls. We think this is very unlikely in a chronic and recurrent condition such as migraine. We also included a question about head traumatism to see if the patients with stroke were likely to pay more attention to head diseases than the controls: head traumatism was reported by fewer of the patients with stroke than by the controls $(17 v 28, \mathrm{p}=$ $0 \cdot 12$ ). We therefore do not think that our results can be explained by recall bias.

In conclusion, we found that migraine was not a significant risk factor for ischaemic stroke in the whole sample. There was, however, a significant association between ischaemic stroke and migraine in younger women. This result, if confirmed, would justify active detection and, if possible, correction of other cerebrovascular risk factors-particularly smoking -in young women with migraine.

This study was supported by a grant from the Assistance Publique-Hôpitaux de Paris (CIRC No I-920304). We thank Stuart Rapoport and to Libby Macintyre for their help in preparing the manuscript.

1 Tatemichi TK, Mohr JP. Migraine and stroke. In: Barnett HJM, Mohr JP, Stein BM, eds. Stroke: pathophysiology, diagnosis and management. Vol 2. Stein BM, eds. Stroke: pathophysiology, diagnosis

2 Couch JR, Hassanein RS. Platelet aggregability in migraine. Neurology Couch JR, Hassan

3 Kalendovsky Z, Austin J, Steele P. Increased platelet aggregability in young patients with stroke. Arch Neurol 1975;32:13-20.

4 Collaborative Group for the Study of Stroke in Young Women. Oral contraceptives and stroke in young women. Associated risk factors. $尹 A M A$ 1975;231:718-22.

5 Henrich JB, Horwitz RI. A controlled study of ischaemic stroke risk in migraine patients. $f$ Clin Epidemiol 1989;42:773-80.

6 International Headache Society. Classification and diagnostic criteria for headache disorders, cranial neuralgias and facial pain. Cephalalgia 1988;8 (suppl 7):1-96.

7 World Health Organization Task Force on Stroke and other Cerebrovascular Disorders. Recommendations on stroke prevention, diagnosis and therapy. Stroke 1989;20:1407-31.

8 SAS Institute. SAS user's guide: statistics. Version 6. Vol 1. Cary, North Carolina: SAS Institute, 1990.

9 Dixon WJ, ed. BMDP statistical software. Berkeley: University of California Press, 1983.

10 Breslow NE, Day NE. Statistical methods in cancer research. Vol 1. The analysis of case-control studies. Lyons: International Agency for Research on Cancer, 1980

11 Rasmussen BK, Jensen R, Schroll M, Olesen J. Epidemiology of headache in 
a general population. A prevalence study, f Clin Epidemiol 1991;11: 1147-57.

12 Waters W/E. Headache and blood pressure in the community. BMF 1971;: 142-3.

13 Weiss NS. Relation of high blood pressure to headache, epistaxis and selected other symptoms: the United States Health Examination survey of adults. N Engl Y Med 1972;287:631-3.

14 Chen TC, Leviton A, Edelstein S, Ellenberg JH. Migraine and other diseases in women of reproductive age. Arch Neurol 1987;44:1024-8.
15 Markush RE, Karp HR, Heyman A, O'Fallon WM. Epidemiologic study of migraine symptoms in young women. Neurology 1975;25:430-5.

16 Ziegler DK, Hassanein R, Couch JR. Characteristics of life headache histories in a non-clinic population. Neurology 1977;27:265-9.

17 Gill JS, Shipley MJ, Tsementzis SA, Hornby R, Gill SK, Hitchcock ER, et al Cigarette smoking. A risk factor for hemorrhagic and non hemorrhagic stroke. Arch Intern Med 1989;149:2053-7.

(Accepted 26 May 1993)

\title{
Muslims with non-insulin dependent diabetes fasting during Ramadan: treatment with glibenclamide
}

\author{
J Belkhadir, H El Ghomari, N Klöcker, A Mikou, M Nasciri, M Sabri
}

Medical Department E, University Hospital Ibn Sina, Rabat, Morocco $\mathrm{J}$ Belkhadir, professor

Department of Endocrinology and Metabolic Diseases, University Hospital Ibn Rochd, Casablanca, Morocco

H El Ghomari, physician

Hoechst AG, Medical Services Corporate, K607; D-6230 Frankfurt, Germany

N Klöcker, physician

Clinic for Endocrinology and Diabetology, Hakim, Casablanca

A Mikou, physician

Clinic for Endocrinology and Diabetology, 2 bd Zerktouni, Casablanca

M Nasciri, physician

Department of

Endocrinology and

Metabolic Diseases,

Polyclinic CNSS Ziraoui,

Casablanca

M Sabri, physician

Correspondence to: Dr Klöcker.

BMF 1993;307:292-5
Abstract

Objective-To compare the efficacy of two glibenclamide regimens in patients with non-insulin dependent diabetes who were fasting during Ramadan and regular glibenclamide treatment in the nonfasting group.

Design-Non-randomised control group of patients who did not fast during Ramadan and two groups of patients who fasted randomised equally to one of two regimens: to take their usual morning dose of glibenclamide in the evening and their usual evening dose before dawn; or to follow this pattern but to reduce the total dose by a quarter.

Setting-Two university hospitals, one private hospital, and two private clinics in Casablanca and Rabat, Morocco.

Subjects -591 diabetic patients (198 men, 391 women, two unspecified) with similar duration of diabetes and length and amount of glibenclamide treatment, of whom 542 completed the study.

Main outcome measures-Serum fructosamine and total glycated haemoglobin concentrations and number of hypoglycaemic events.

Results-At the end of Ramadan there were no significant differences between the groups in fructosamine concentration $(400 \mu \mathrm{mol} / /$ in controls and $381 \mu \mathrm{mol} / \mathrm{h}$ and $376 \mu \mathrm{mol} / \mathrm{h}$ in the fasting groups); percentage of glycated haemoglobin $(14 \cdot 7 \%, 14.0 \%$, and $13.6 \%$ ); or number of hypoglycaemic events during Ramadan (11, 14, and 10).

Conclusion-Glibenclamide is effective and safe for patients with non-insulin dependent diabetes who fast during Ramadan. The easiest regimen is to take the normal morning dose (together with any midday dose) at sunset and any evening dose before dawn.

\section{Introduction}

About one billion people worldwide follow Islam, a basic principle of which is fasting from sunrise to sunset for one lunar month during Ramadan. This poses obvious problems for patients with diabetes, ${ }^{12}$ who mostly prefer not to accept the exemptions allowed for patients with certain illnesses. ${ }^{3}$ Although the prevalence of diabetes may be $3-5 \%$ in Islamic countries, ${ }^{4}$ the only studies of the problems experienced by diabetic patients during Ramadan have been on small groups (fewer than 60 patients) treated with several drugs. ${ }^{5-8}$ At least one of the studies examined only men. ${ }^{6}$ Two studies of fasting among healthy subjects also examined only men.910 We have therefore conducted a randomised controlled trial of different treatment regimens in a group of patients with non-insulin dependent diabetes living in two Moroccan cities who were being treated with glibenclamide.

\section{Patients and methods}

The study was performed at one university hospital, one private hospital, and two private clinics in Casablanca and one university hospital in Rabat. These sites were chosen to guarantee the inclusion of all social classes. The study lasted from 27 January to 8 May 1992 to include a run in and follow up of about four weeks each as well as the month of Ramadan (6 March to 5 April). During this time patients were asked to visit a study centre four times in predefined time windows of about one week each: at the start of run in (27 January to 7 February), at the start of Ramadan (24 February to $5 \mathrm{March}$ ), at the end of Ramadan (26 March to 4 April), and at the end of follow up (22 April to 8 May). Altogether 591 patients of both sexes were recruited. They were aged 33-80 (mean 55.5) years, had established non-insulin dependent diabetes (mean duration 7.6 years), and had been treated with glibenclamide $7 \cdot 5-20 \mathrm{mg}$ (mean $11 \mathrm{mg}$ ) for at least six months. Thus newly diagnosed diabetic patients and those whose response to glibenclamide was not yet known were excluded. The study centres were asked to recruit twice as many patients who planned to fast during Ramadan as those who planned not to fast.

All the selected patients gave their informed consent to the study. They were divided into three groups. Those who had elected not to fast during Ramadan acted as a substitute for a randomised control group, which would have created some ethical problems. The remaining patients, who had decided to fast, were randomised consecutively with sealed envelopes to one of two regimens. In one group patients took their normal daily doses of glibenclamide but reversed the pattern of doses so that they took their usual morning dose at $7 \mathrm{pm}$, after the break of fasting, and their usual evening dose at $4 \mathrm{am}$, with the last meal before fasting. The 126 patients in this group who had been taking another dose at midday, a common practice in the Mediterranean and tropical countries, added this to the dose taken in the evening. The patients in the other group also reversed their normal pattern of doses but took only $75 \%$ of their normal total daily dose of glibenclamide by reducing the amount taken in the morning. The 122 patients in this group who had been taking a dose at midday" divided this dose equally between the morning and evening doses.

At each visit to a study centre the patients' weight, blood pressure, and pulse rate were measured, and blood samples were taken for laboratory analysis. Patients' hypoglycaemic events were assessed retrospectively and rated on a six point scale. As far as possible the patients were asked to monitor glucose concentrations in their urine and were supplied with test strips. They were asked to monitor the first spontaneous release of urine after the start of fasting and after breaking their fast, to record the values in a booklet, and to discuss the results at the next visit. This 